\title{
Análise florística e estrutura de florestas de Várzea no estuário amazônico.
}

\author{
Samuel Soares de ALMEIDA ${ }^{1}$, Dário Dantas do AMARAL ${ }^{1}$, Antonio Sérgio Lima da SILVA ${ }^{1}$
}

\begin{abstract}
RESUMO
Este trabalho apresenta os resultados de análise fitossociológica e da estrutura, feita em 4 inventários florísticos executados em parcelas de 1 hectare de florestas inundáveis de várzea localizadas na área do estuário e do baixo Amazonas. As florestas de várzea do estuário albergam uma riqueza de espécies relativamente baixa em relação a outras áreas da região como as florestas de terra firme. No entanto a estrutura de tamanho é considerável, com as árvores atingindo elevada biomassa vegetal. Provavelmente isto é devido ao aporte constante de nutrientes através dos sedimentos que viajam milhares de quilômetros de distância desde as nascentes andinas até o delta do rio Amazonas. As florestas inundáveis de várzea são dominadas por poucas espécies, algumas com muitos indivíduos, como o açaí (Euterpe oleracea) e o murumuru (Astrocaryum murumuru), outras com árvores muito grandes como a pitaíca (Swartzia polyphylla), pracuúba (Mora paraensis) e a seringueira (Hevea brasiliensis). A ucuúba (Virola surinamensis), uma espécie que apresenta populações ameaçadas pela exploração madeireira, parece apresentar tanto indivíduos grandes como elevada densidade. As florestas de várzea apresentam baixa similaridade entre si, provavelmente decorrente da imensa variação do ambiente de várzea nos rios, paranás, ilhas e lagos, como os efeitos de zonação, altura de inundação, salinidade, velocidade da água, entre outros fatores. Estratégias de seleção de áreas de várzea para conservação devem levar em conta a variação ambiental, o grau de interferência humana e a diversidade local e entre ambientes.
\end{abstract}

\section{PALAVRAS-CHAVE}

várzeas, florestas inundáveis, estuário, fitossociologia, Amazônia

\section{Floristic analysis and structure of tidal flooded forests in the amazonian estuary.}

\begin{abstract}
This work presents results of the analysis made in four 1-hectare plots of floristic inventory in the flooded forests located in the delta and lower basin of the Amazon river. The flooded forests, so called "várzea" forests, harbor a relatively low species richness in relation to other areas such as "terra firme" forests. However the structure in size is considerable, with trees attaining high plant biomass. Probably that is due to the constant contribution of nutrients through the sediments that travel thousands of kilometers from the watersheds of the Andes to the delta of the Amazon river. The flooded forests of "várzea" are dominated by very few species (oligarchic forests), some they with so many individuals such us the açai (Euterpe oleracea) and the muru-muru (Astrocaryum murumuru) palms, another with very big trees like the pitaica (Swartzia polyphylla), pracuúba (Mora paraensis) and the seringueira (Hevea brasiliensis). The ucuúba (Virola surinamensis), a species whose populations are threatened by the timber logging, it has both large trees and great abundance. The delta flooded forests have low similarity when compared to each other, probably due to the immense variation of the environment in rivers, channels, islands and lakes. Local effects such as topographic gradient, flood height, salinity, velocity of the water can strongly affect the diversity, abundance and distribution of plants. Strategies of selection of várzea areas for conservation should take into account the environmental variation, the degree of human interference and both local and the diversity between habitats.
\end{abstract}

\section{KEY WORDS}

flooded forests, "varzeas", estuary, phytossociological analysis, Amazonia forest diversity

\footnotetext{
${ }^{1}$ Pesquisadores Museu Paraense Emílio Goeldi, Coordenadoria de Botânica; Av. Magalhães Barata 376, Nazaré, 66.040-170, Fone : (0xx) 91 21769091, Fax: (0xx) 91 2742967, Internet: http://www.museu-goeldi.br
} 


\section{ACTA \\ AMAZONICA}

ANÁLISE FLORÍSTICA E ESTRUTURA DE FLORESTAS

DE VÁRZEA NO ESTUÁRIO AMAZÔNICO

\section{INTRODUÇÃO}

As florestas de várzea dominam a paisagem na zona estuarina amazônica (Anderson 1991; Padoch et al. 2000). Elas estão concentradas na planície de inundação, cujos sedimentos começaram a se depositar no holoceno durante os últimos 10.000 anos. Em alguns locais estes sedimentos são tão recentes que ainda não estão consolidados nem estratificados (Alfaia \& Falcão 1993). As partículas em suspensão são de material argiloso que confere à água uma coloração pardo-amarelada, classificada pelos limnologistas como água branca ou barrenta (Sioli 1984). Este material é parental de solos andinos e préandinos, localizados a cerca de $3.500 \mathrm{~km}$ a oeste.

O fluxo das marés no estuário eleva o nível da água entre 2 e $4 \mathrm{~m}$, dependendo do período do ano. Geralmente as marés da época mais chuvosa atingem as cotas mais altas, face ao efeito aditivo do refluxo oceânico e da elevada descarga hídrica do rio nesta época do ano.

Apesar das limitações ambientais, as várzeas do estuário englobam diversas formas de vida. A riqueza de espécies não é elevada como na terra firme, embora contemple alguns elementos florísticos restritos e característicos (Almeida 1996).

A deposição de sedimentos, formação de bancos e colonização pioneira são processos muito dinâmicos nas várzeas amazônicas (Kalliola et al. 1991). As primeiras formas de vida vegetal a colonizar os bancos de sedimentos recémdepositados são as ervas aquáticas pioneiras, especialmente gramíneas e ciperáceas, que se encarregam de cobrir o solo e fixar o sedimento. Logo depois a sucessão se inicia com a colonização de plantas lenhosas, como os arbustos, lianas e ervas rizomatosas arborescentes, que aumentam a cobertura vegetal do solo e consolidam o serviço iniciado pelas pioneiras. O estrato arbóreo climácico cria e mantém o microclima no interior das várzeas, abrigando a fauna associada composta por artrópodes, aves limnícolas, peixes, mamíferos aquáticos e outros organismos que utilizam as plantas e suas estruturas para se abrigar e se reproduzir.

As várzeas são ambientes frágeis e de difícil recuperação uma vez alteradas pela intervenção humana (Junk 1997). O grau de resiliência é baixo e a remoção da cobertura vegetal pode simplesmente levar a perda do habitat, face à importância ecológica e estrutural que as plantas desempenham para a manutenção desse ecossistema.

O ambiente de várzea no estuário serve como suporte sócioeconômico para um contingente humano considerável (Hiraoka 1992; Goulding et al. 1995). A maioria das populações dos municípios do arquipélago do Marajó, rio Pará e nos baixos cursos dos rios Amazonas, Acará, Moju e Tocantins vive literalmente sobre as várzeas. Alguns desses municípios comportam quase 100 mil pessoas como Abaetetuba, Cametá e Breves. As principais atividades econômicas são o extrativismo vegetal, principalmente frutos de açaí, palmito, exploração madeireira, pesca, captura de camarão e agricultura familiar (Anderson 1991).

Este trabalho tem como objetivo analisar algumas características físicas e fitossociológicas de várzeas do estuário amazônico.

\section{MÉTODOS}

\section{Abrangência e características físicas da área de estudo.}

A área de estudo abrange a parte sul do estuário amazônico, incluindo parte do arquipélago do Marajó, foz dos rios Pará e Xingu. Esta área está compreendida entre os paralelos $00^{\circ} 15^{\prime} \mathrm{S}-02^{\circ} 38^{\prime} \mathrm{S}$ x 48 $39^{\circ} \mathrm{W}$ - 51 $1^{\circ} 36^{\prime} \mathrm{W}$ (Tabela 1 ). Os inventários analisados estão localizados nos municípios de Afuá, Chaves, Barcarena e Senador José Porfírio.

Todas as várzeas analisadas estão sobre sedimentos recentes do quaternário holocênico. Seus solos são hidromórficos do tipo glei húmico, com fertilidade de média a elevada, médio teor de matéria orgânica e boa capacidade de troca catiônica. Em geral são mal drenados, sem estratificação do perfil vertical e com elevado teor de argila e silte. Nesta área o tipo climático predominante é Af (classificação de Köppen), com total pluviométrico em torno de $2.800 \mathrm{~mm}$ anuais, distribuídos principalmente entre os meses de janeiro e maio. A temperatura média fica em torno de $26^{\circ} \mathrm{C}$ e a umidade relativa do ar média anual fica em torno de $87 \%$. A cobertura de nuvens na região é elevada durante o ano inteiro.

\section{Inventários analisados}

Foram analisados 4 inventários florísticos quantitativos na área indicada, compreendendo várzeas localizadas nas margens de rios como as parcelas do município de Barcarena (rio Pará) e Xingu (baixo rio Xingu, município de Senador José Porfírio) e ilhas e paranás de várzea nos municípios de Chaves e Afuá (ilha do Cajuúna). Os inventários analisados são amostras de 1 hectare $\left(10.000 \mathrm{~m}^{2}\right)$ de floresta de várzea, com limite mínimo

Tabela 1 - Informações locacionais sobre os inventários de florestas de várzea analisados. Limite de inclusão a partir de $10 \mathrm{~cm}$ de DAP. Estado do Pará.

\begin{tabular}{llccc}
\hline \hline No. & Local & $\begin{array}{c}\text { Coordenadas } \\
(\mathrm{S}, \mathrm{W})\end{array}$ & $\begin{array}{c}\text { Área } \\
\text { (ha) }\end{array}$ & Fonte \\
\hline 1 & Chaves, Marajó & $00^{\circ} 1^{\prime}, 49^{\circ} 39^{\prime}$ & 1,0 & Almeida, Amaral \& Silva 2002 \\
2 & Ilha do Cajuúna, Afuá & $00^{\circ} 05^{\prime}, 50^{\circ} 20^{\prime}$ & 1,0 & Almeida, Amaral \& Silva 2002 \\
3 & Ilha Trambioca, Rio Pará, Barcarena & $01^{\circ} 26^{\prime}, 48^{\circ} 39^{\prime}$ & 1,0 & Amaral et al. (não publ.) \\
4 & Baixo rio Xingu, Senador José Porfírio & $02^{\circ} 38^{\prime}, 51^{\circ} 56^{\prime}$ & 1,0 & Este trabalho \\
\hline \hline
\end{tabular}




\section{ACTA \\ AMAZONICA}

ANÁLISE FLORÍSTICA E ESTRUTURA DE FLORESTAS DE VÁRZEA NO ESTUÁRIO AMAZÔNICO de inclusão de DAP (diâmetro a altura do peito, medido a 1,30 $\mathrm{m}$ de altura) a partir de $10 \mathrm{~cm}$ (Tabela 1).

\section{Análises fitossociológicas}

Os parâmetros de diversidade e de fitossociologia analisados (Shannon \& Wiener 1949; Mueller-Dombois \& Ellenberg 1974; Pires-O Brien \& O'Obrien 1995) e suas respectivas equações estão indicados a seguir:

Índice de Diversidade Shannon \& Wiener (1949)

$\mathrm{H}^{\prime}=-\stackrel{̊}{\mathrm{a}}\left(\mathrm{n}_{\mathrm{i}} / \mathrm{N}\right) \ln \left(\mathrm{n}_{\mathrm{i}} / \mathrm{N}\right)$

$\mathrm{n}_{\mathrm{i}}=\mathrm{n}^{\mathrm{o}}$ de indivíduos amostrados para a espécie $i$

$\mathrm{N}=\mathrm{n}^{\circ}$ total de indivíduos amostrados

$\ln =$ logaritmo neperiano

Abundância Relativa (\% DR)

$\mathrm{DR}=\mathrm{N}^{\circ}$ de indivíduos da espécie $/ \mathrm{n}^{\circ}$ total de indivíduos x 100 .

\section{Freqüência Relativa (\% FR)}

$\mathrm{FR}=\mathrm{N}^{\mathrm{o}}$ de parcelas em que ocorre a espécie $/ \mathrm{n}^{\circ}$ total de parcelas x 100 .

Dominância Relativa (\% DoR)

DoR = Área basal total da espécie / área basal total de todas as espécies $\times 100$

Valor de Importância Específica (\%IVI)

IVI $=$ DR $\%+$ FR $\%+$ DoR $\% / 3$

Valor de Cobertura (VC)

$\mathrm{VC}=\mathrm{DR} \%+$ DoR \% / 2

Área Basal (AB m²/ha)

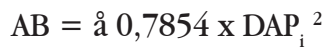

$\mathrm{DAP}_{\mathrm{i}}=$ diâmetro do fuste de cada árvore, medido à 1,30 m do solo.

Volume de Madeira com casca (Vol, $\mathrm{m}^{3} / \mathrm{ha}$ )

$\mathrm{V}=0,5498 * \operatorname{DAP}_{\mathrm{i}} 2 * \mathrm{~h}_{\mathrm{i}} * 0,7$

$\mathrm{h}_{\mathrm{i}=}$ altura do fuste de cada árvore amostrada / ha

$0,7=$ Fator de forma do fuste

Índice de Similaridade de Sørensen (I)

$I_{s=}(2 * C / A+B) * 100$

$\mathrm{A}$ e $\mathrm{H}=\mathrm{n}^{\circ}$. de espécies nas amostras $\mathrm{A}$ e $\mathrm{B}$

$\mathrm{C}={ }^{\circ}$. de espécies comuns às duas amc stras

\section{RESULTADOS E DISCUSSÃO}

\section{Os tipos de várzeas amazônicas}

As várzeas amazônicas podem ser divididas em 2 grupos de acordo com o sistema hídrico (Prance 1979). As várzeas de marés, que estão sujeitas aos pulsos de inundação diária; e as várzeas sazonais, que são submetidas ao ciclo anual de enchente e vazante (Tabela 2). As várzeas sob análise constituem um grupo à parte e se distribuem ao longo do estuário até a confluência com o rio Xingu. À montante do estreito de Óbidos, as várzeas não têm mais a influência das marés e se tornam sazonais, com picos de enchente entre maio e julho e de vazante entre novembro e janeiro. Nas várzeas sazonais a altura de inundação é maior $(5-10 \mathrm{~m})$ e os ciclos de enchente e vazante apresentam aproximadamente um período de 6 meses cada.

Os altos cursos de alguns rios de água branca como o Amazonas, Ucayali, Marañon, Madre de Dios (Peru), Beni (Bolívia), Juruá e Purus (Brasil) são meandrados, com elevada velocidade de escoamento e cota de inundação que pode atingir entre 10 e $20 \mathrm{~m}$. Devido correram numa zona de transição altimétrica entre as zonas submontanhosa e das terras baixas de planície, os rios meandrados possuem uma dinâmica hidrológica considerável (Kalliola et al. 1991), com elevada taxa de erosão e deposição de sedimentos, especialmente aqueles com granulometria maior. Os sedimentos menores são transportados rio abaixo e depositados a centenas de quilômetros à jusante.

Em geral os solos quaternários de várzea são ricos em bases trocáveis e em alguns micro-nutrientes, embora os solos holocênicos, mais recentes, apresentem maiores níveis de fertilidade quando comparados àqueles de origem pleistocênica (Ayres 1993).
Tabela 2 - Tipos de vegetação sujeitos à inundação, modificado de Prance (1979).

\begin{tabular}{|c|c|c|}
\hline A & Floresta periodicamente inundada & \\
\hline I & Inundação por ciclos anuais regulares de rios & \\
\hline & i Floresta inundada por água branca & 1. Várzea estacional \\
\hline & ii Floresta inundada por água preta e clara & 2. Igapó estacional \\
\hline II & Inundação por movimento de maré & \\
\hline & i Água salgada & 3. Manguezal \\
\hline & ii Água doce represada por marés & 4. Várzea de marés \\
\hline & iii Água salobra & 4. Várzea de estuário \\
\hline III & Inundação por chuva irregular & $\begin{array}{l}\text { 5. Floresta de } \\
\text { planície inundável }\end{array}$ \\
\hline B & Floresta permanentemente inundadaa & \\
\hline & i Água branca & 6. Floresta de pântanos \\
\hline & ii Água preta ou clara & 7. Igapó permanente \\
\hline
\end{tabular}




\section{Características florísticas e diversidade das várzeas}

A vegetação que cresce sobre estes sedimentos é adaptada às condições de inundação, causada pelo fluxo diário das marés. Seus elementos florísticos possuem mecanismos de regulação osmótica da água, permitindo suas raízes e seus caules conviverem com pelo menos 12 horas de inundação a cada dia, inclusive certo grau de salinidade (Almeida 1996). São freqüentes as adaptações ecológicas, fisiológicas e morfológicas para vegetar sob inundação onde o suprimento de oxigênio é precário. Entre as adaptações eco-fisiológicas, pode-se citar a intensa troca de gases pelas lenticelas caulinares, para compensar a hipoxia ao nível de raízes; o controle da abertura estomática nas folhas, a perda total ou parcial de folhas (deciduidade) e o ritmo de crescimento sazonal das plantas regulado pelo período de inundação. Entre as adaptações morfoecológicas pode ser exemplificada a alta freqüência de sapopemas (raízes tabulares), que facilita a sustentação de grandes árvores; a presença de raízes e estruturas aéreas como rizóforos, penumatóforos e haustórios.

Em alguns pontos do estuário é possível visualizar a distribuição espacial da diversidade vegetal através da zonação existente ao longo da topossequência, a partir das cotas mais baixas. Neste ponto pode-se observar as macrófitas aquáticas inclusive os capins flutuantes (canaranas), vindo logo depois as lianas e ervas arborescentes. Nas cotas mais altas aparece a formação florestal das várzeas, composta de diversas espécies de árvores características como a pracuúba (Mora paraensis), o ceru (Allantoma lineata), anani (Sympbonia globulifera) dentre outras, e palmeiras como o açaí (Euterpe oleracea), buriti (Mauritia flexuosa), muru-muru (Astrocaryum murumuru), jupati (Raphia taedigera (Mart.) Mart.) e algumas vezes o patauá (Oenocarpus bataua).

A listagem geral das espécies registradas nos 4 locais de várzeas estuarinas estudados estão no Anexo I.

Nas quatro áreas estudadas foram inventariados 2.911 indivíduos, representados por 164 espécies que estão distribuídas em 39 famílias botânicas (Tabela 3). De acordo com a Tabela 3, a maior riqueza em termos florísticos foi registrada na várzea de Barcarena, apresentando maiores números tanto de espécies (78) como de famílias (30), resultando em índice de diversidade (3,52 nats) também superior em relação aos demais locais. Estruturalmente a várzea do Xingu corresponde aquela de maior destaque, com área basal $\left(38,65 \mathrm{~m}^{2} \cdot \mathrm{ha}^{-1}\right)$ bem superior às outras áreas. Esta relevância estrutural e fitossociológica pode ser atribuída à presença dominante de Hevea brasiliensis, tendo em vista tratar-se de uma área natural de seringal.

As florestas de várzea apresentam riqueza de espécies relativamente pequena em relação aos ambientes de terra firme. Em compensação algumas delas apresentam elevada área basal e biomassa, resultado do alto teor de nutrientes dos solos deste ambiente. Nas parcelas analisadas, a riqueza variou de 36 (Chaves) a 78 espécies (Barcarena) (Tabela 3). No geral esta riqueza específica pode ser influenciada pelas condições limitantes locais como altura de inundação, erosão do solo e teor de salinidade que aumenta nas várzeas mais próximas do oceano, como é o caso de Chaves, na ilha do Marajó.

As florestas de várzea analisadas apresentam baixa similaridade entre si, talvez devido à imensa variação do ambiente de várzea em rios, paranás, ilhas e lagos, como os efeitos de zonação, altura de inundação, salinidade, velocidade da água, entre outros fatores. A similaridade entre as áreas parece manter relação com a distância entre elas, pois parcelas mais afastadas (Xingu e Chaves), apresentaram a menor similaridade florística $(8,0 \%)$, enquanto várzeas mais próximas apresentaram maior similaridade (Chaves e Cajuúna, 25,0\%; Cajuúna e Barcarena, 32,0 \%) (Tabela 4).

\section{Análise fitossociológica das várzeas de estuário}

Os principais parâmetros fitossociológicos e estruturais das várzeas estudadas estão detalhados na Tabela 5.

As várzeas estuarinas são caracterizadas pela presença de oligoespécies. Essas espécies apresentam considerável número de indivíduos por unidade de área. Nos 4 locais estudados, as 5 espécies mais representativas apresentaram mais de 50 \% do Valor de Importância total, com exceção da parcela inventariada em Barcarena (Tabela 5). Isto significa afirmar que um reduzido número de espécies $(10,2$ \% em média) domina a estrutura das comunidades e, por

Tabela 3 - Parâmetros comparativos de estrutura e diversidade das florestas de várzea analisadas no presente estudo. Parcelas de 1 hectare.

\begin{tabular}{|c|c|c|c|c|c|c|}
\hline LOCAIS & $\begin{array}{c}\text { Área } \\
\text { Basal(m2.ha-1) }\end{array}$ & $N^{\circ}$ Espécies & $\begin{array}{l}\text { No Esp. } \\
\text { Exclusivas }\end{array}$ & $\mathrm{N}^{\circ}$ Indivíduos & $\mathrm{N}^{\circ}$ de Famílias & Diversidade H' (em nats) \\
\hline Barcarena & 26,48 & 78 & 49 & 735 & 30 & 3,52 \\
\hline Cajuúna & 30,39 & 60 & 29 & 691 & 24 & 2,55 \\
\hline Chaves & 23,99 & 36 & 21 & 809 & 18 & 1,62 \\
\hline Xingu & 38,65 & 42 & 27 & 676 & 23 & 2,85 \\
\hline Total & $\tilde{\mathbf{N}}$ & 164 & 126 & 2.911 & 39 & - \\
\hline
\end{tabular}




\section{ACTA \\ AMAZONICA}

ANÁLISE FLORÍSTICA E ESTRUTURA DE FLORESTAS DE VÁRZEA NO ESTUÁRIO AMAZÔNICO conseguinte, a paisagem dos ambientes inundáveis do estuário e do baixo Amazonas. Euterpe oleracea, Astrocaryum murumuru, Hevea brasiliensis, Pentacletbra macroloba e Virola surinamensis agrupam, juntas, 1.512 indivíduos, correspondendo a 51,94\% do total inventariado (Tabela 5).

Apenas duas espécies (1,22\%), Caryocar microcarpum e Virola surinamensis, foram comuns nas quatro várzeas estudadas. A grande maioria das espécies (126 spp., 76,83\%) ocorreu apenas em uma das áreas. Dez espécies (6,09\%) ocorreram em três áreas e outras 26 (15,85\%) foram registradas em duas áreas (Anexo I).

Dentre as espécies um total de 45 (27,44\%) apresentaram-se como raras nestas várzeas, representadas por somente um individuo, ocorrendo em um dos locais com apenas um indivíduo, dentre elas, Unonopsis guatterioides, Protium polybotrium, Maytenus ebenifolia, Vantanea guianensis, Rinorea neglecta, Poraqueiba guianensis, e Laetia procera (Tabela 5).

Mimosaceae destaca-se como a família de maior riqueza específica (19), seguida de Caesalpiniaceae (13), Chysobalanaceae (11), Clusiaceae (11), Arecaceae (10), Fabaceae (10), Euphorbiaceae (9), Lecythidaceae (6), Meliaceae (6) e Sapotaceae (6). Estas 10 famílias, juntas, correspondem a $61,58 \%$ do total de espécies, enquanto as outras 29 famílias representam as demais espécies. (Figura 1).

Quais os processos bioecológicos do ambiente ou os mecanismos intrínsecos das espécies que levam a esta dominância? Esta é uma questão colocada e que necessita

Tabela 4 - Matriz de percentagem de similaridade de Sørensen entre as 4 áreas estudadas.

\begin{tabular}{lccc}
\hline \hline Parcela & Barcarena & Cajuúna & Chaves \\
\hline Barcarena & & & \\
Cajuúna & 32,0 & & \\
Chaves & 14,0 & 25,0 & \\
Xingu & 20,0 & 22,0 & 8,0 \\
\hline \hline
\end{tabular}

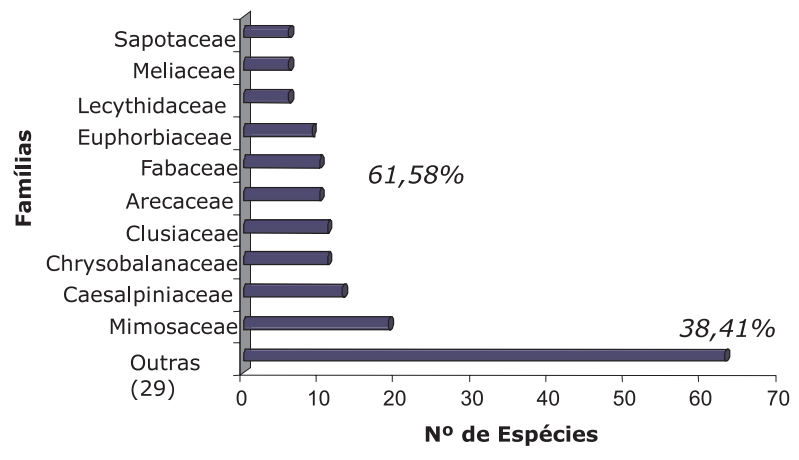

Figura 1 - Distribuição geral do número de espécies por famílias botânicas, considerando todos os quatro inventários. de mais investimento em pesquisa para ser respondida. Provavelmente algumas características de história natural das espécies, como eficiência da dispersão primária de frutos e sementes pela água; capacidade das plantas suportarem forte estresse hídrico e a habilidade mecânica das raízes para se fixarem em substrato pouco consolidado, assim como o sucesso na germinação das sementes e a capacidade que as plântulas teriam para regenerar mesmo sob regime de inundação diária. Quanto ao ambiente, ele deve favorecer a colonização de algumas espécies mais exigentes em nutrientes do solo, mas que possam vegetar em solos mal drenados e sem estrutura pedológica definida.

\section{CONCLUSÃO}

As florestas de várzeas do sistema de águas brancas do estuário apresentam grande variabilidade ambiental, incluindo aquelas que se desenvolvem às margens de rios, paranás, ilhas e lagos. Parte desta variação pode ser explicada também pela altura de inundação, salinidade, velocidade da água dentre outros fatores físicos.

As várzeas do estuário e do baixo Amazonas analisadas apresentam baixa riqueza de espécies, elevada área basal e pequena similaridade entre si.

A diversidade aumenta dos sítios mais extremos do delta (no limite com o oceano) para aqueles localizados mais para o interior, no baixo Amazonas.

As avaliações para priorização de áreas de várzea para conservação devem levar em conta a variação ambiental, o grau de interferência humana e as diversidades dentro (alfa diversidade) e entre os ambientes (beta diversidade).

\section{BIBLIOGRAFIA CITADA}

Almeida, S.S. 1996. Estrutura e florística em áreas de manguezais paraenses: evidências da influência do estuário amazônico. Bol. Mus. Par. Em. Goeldi, ser. Ciênc. Terra 8: 93-100.

Almeida, S.S.; Amaral, D.D.; Silva, A.S.L. 2002. Fitossociologia de florestas de várzea no estuário amazônico.Belém, PA. Museu Emílio Goeldi. Anais do VI Ecolab, Midia CD-ROM, 12 p.

Alfaia, S. S.; N. P. Falcão. 1993. Estudo da dinâmica de nutrientes em solos de várzea da Ilha do Careiro no estado do Amazonas. Amazoniana 12: 551-563.

Anderson, A. 1991. Forest management strategies by rural inhabitants in the Amazon estuary. Pages 351-360 in A. GómezPompa, T. C. Whitmore, and M. Hadley, eds. Rain Forest Regeneration and Management. The Parthenon Publishing Group, Paris.

Ayres, J. M. 1993. As matas de várzea do Mamirauá. In. Sociedade Civil Mamirauá (ed.), Estudos de Mamirauá, vol. 1. CNPq, Brasília, pp. 1 - 23.

Goulding, M, N.J.H. Smith; D.J. Mahar. 1995. Floods of Fortune: Ecology and economy along the Amazon. Columbia University Press, New York. 


\section{ACTA \\ AMAZONICA \\ ANÁLISE FLORÍSTICA E ESTRUTURA DE FLORESTAS \\ DE VÁRZEA NO ESTUÁRIO AMAZÔNICO}

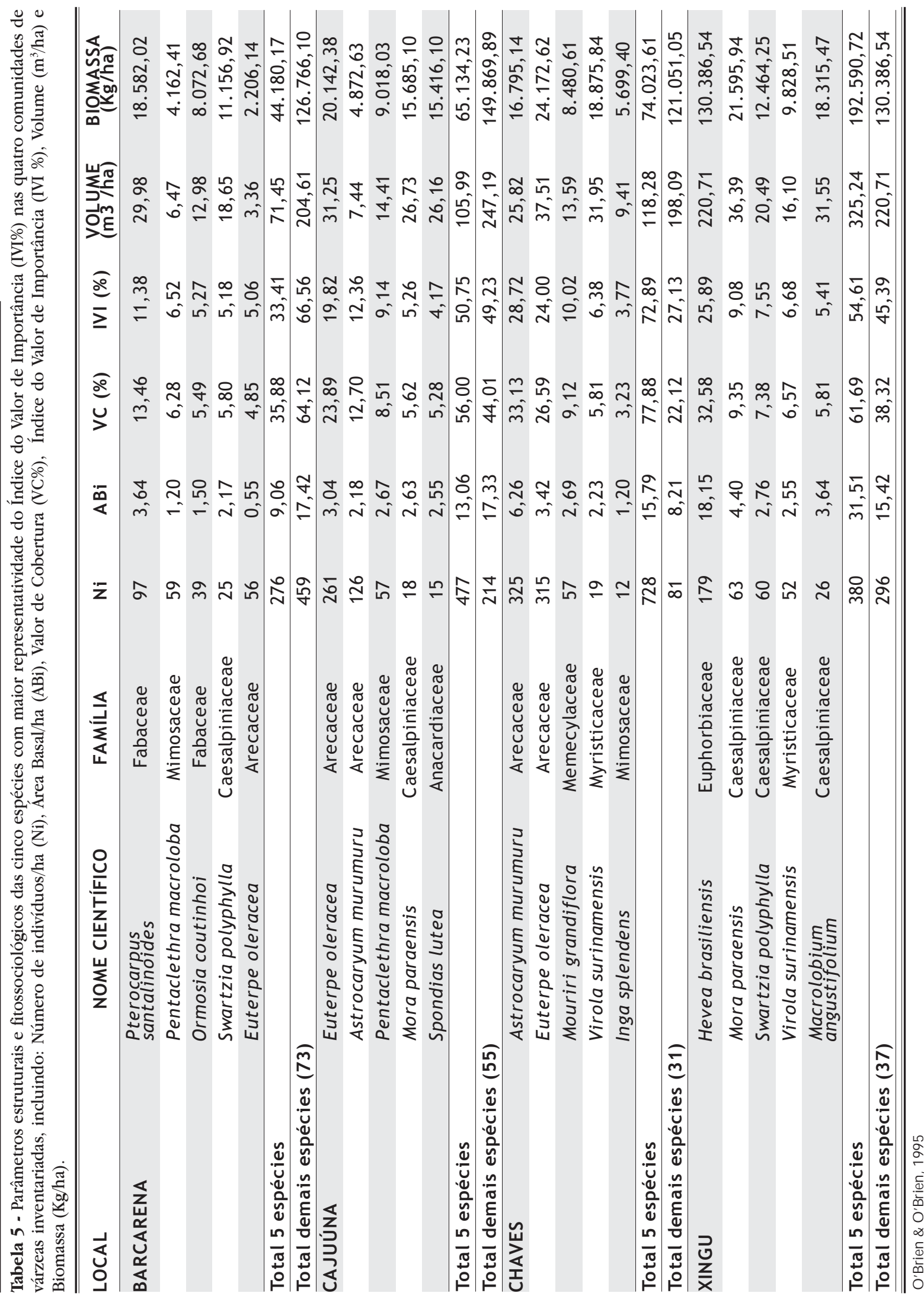


Hiraoka, M. 1992. Caboclo resource management: a review. In K. Redford and C. Padoch, eds. Conservation in the Neotropics. Columbia University Press, New York.

Junk W.J. 1997. The Central Amazon Floodplain: Ecology of a Pulsing System. Springer, New York.

Kalliola, R., J. Salo, M. Puhakka; M. Rajasilta. 1991. New site formation and colonizing vegetation in primary succession on the western Amazon floodplains. Journal of Ecology 79: 877-901.

Mueller-Dombois, D.; Ellemberg, H. 1974. Aims and methods of vegetation ecology. New York, John Willey and Sons (ed.), pp. 45-135.

Padoch, C., M. Ayres, M. Pinedo-Vasquez; A. Henderson, eds. 2000. Várzea: Diversity, Development, and Conservation in Amazonia's Whitewater Floodplains. The New York Botanical Garden Press, New York.

ANEXO I - VEJA TABELA NA PÁGINA 520
Pires-O' Brien, M. J.; O’ Brien, C. M. 1995. Ecologia e modelamento de florestas tropicais. FCAP. Serviço de Documentação e Informação. 400p.

Prance, G. T. 1979. Notes on the vegetation of Amazonia III. The terminology of Amazonian forest types subject to inundation. Brittonia 31: 26-38.

Shannon, C. E.; Wiener, W. 1949. The mathematical theory of communication. Urbana. University of Illinois Press. 117p.

Sioli, H., ed. 1984. The Amazon - Limnology and landscape ecology of a mighty tropical river and its basin. Junk, Dordrecht.

\section{RECEBIDO EM: 09/03/04 \\ ACEITO EM: 30/08/04}




\section{ACTA \\ AMAZONICA \\ ANÁLISE FLORÍSTICA E ESTRUTURA DE FLORESTAS \\ DE VÁRZEA NO ESTUÁRIO AMAZÔNICO}

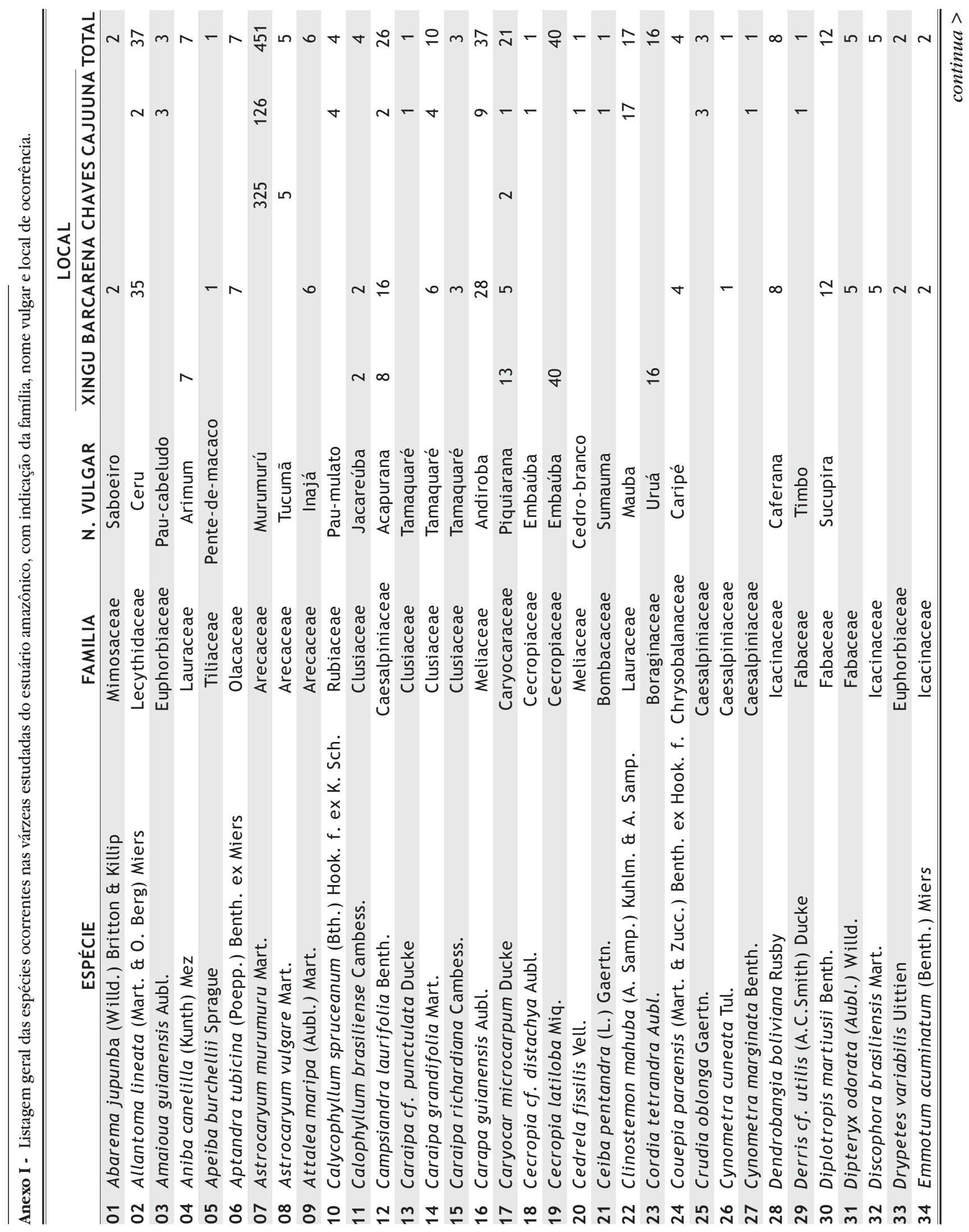




\section{ACTA \\ AMAZONICA

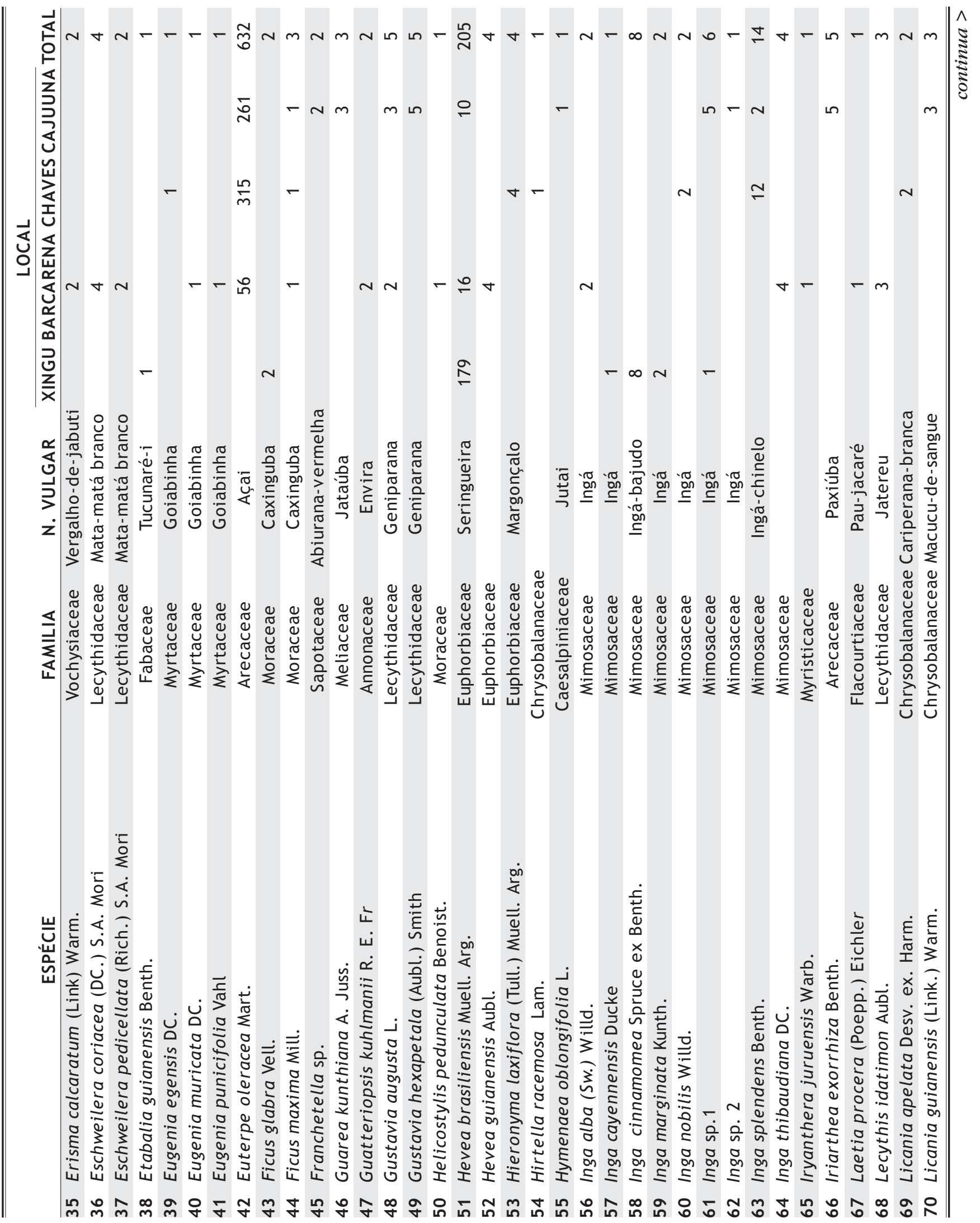




\section{ACTA \\ AMAZONICA \\ ANÁLISE FLORÍSTICA E ESTRUTURA DE FLORESTAS \\ DE VÁRZEA NO ESTUÁRIO AMAZÔNICO}

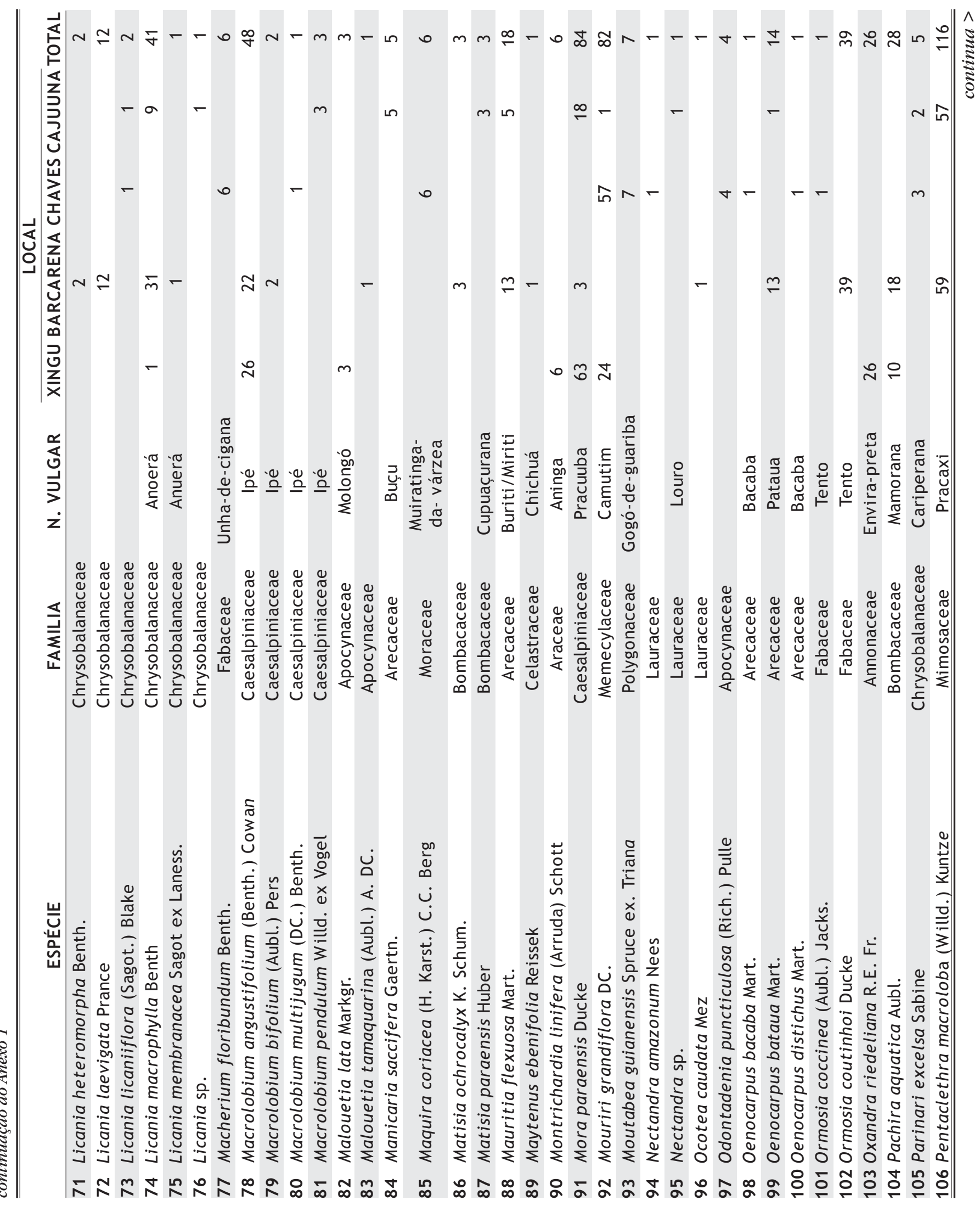




\section{ACTA \\ AMAZONICA

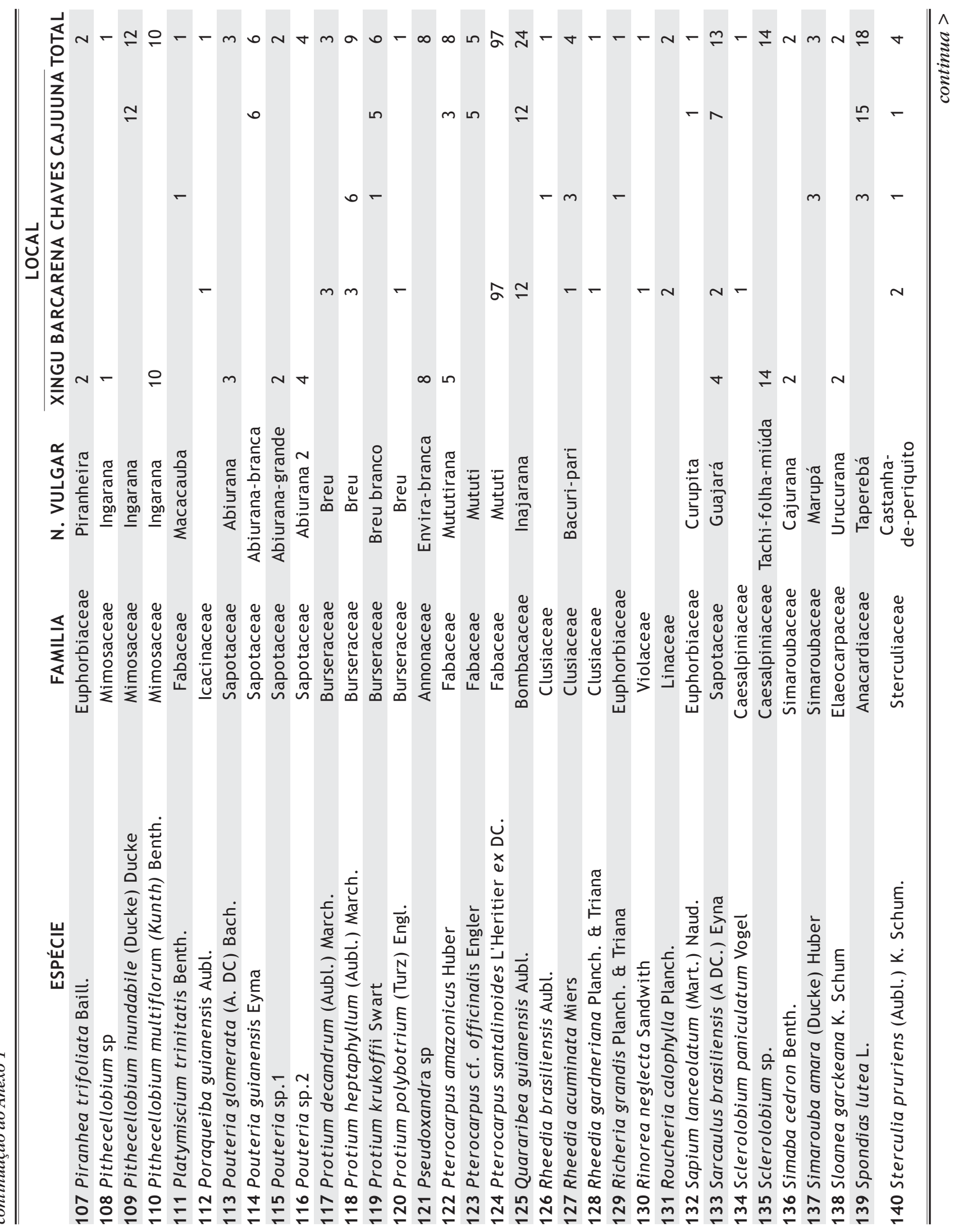




\section{ACTA \\ AMAZONICA \\ ANÁLISE FLORISTICA E ESTRUTURA DE FLORESTAS \\ DE VÁRZEA NO ESTUÁRIO AMAZÔNICO}

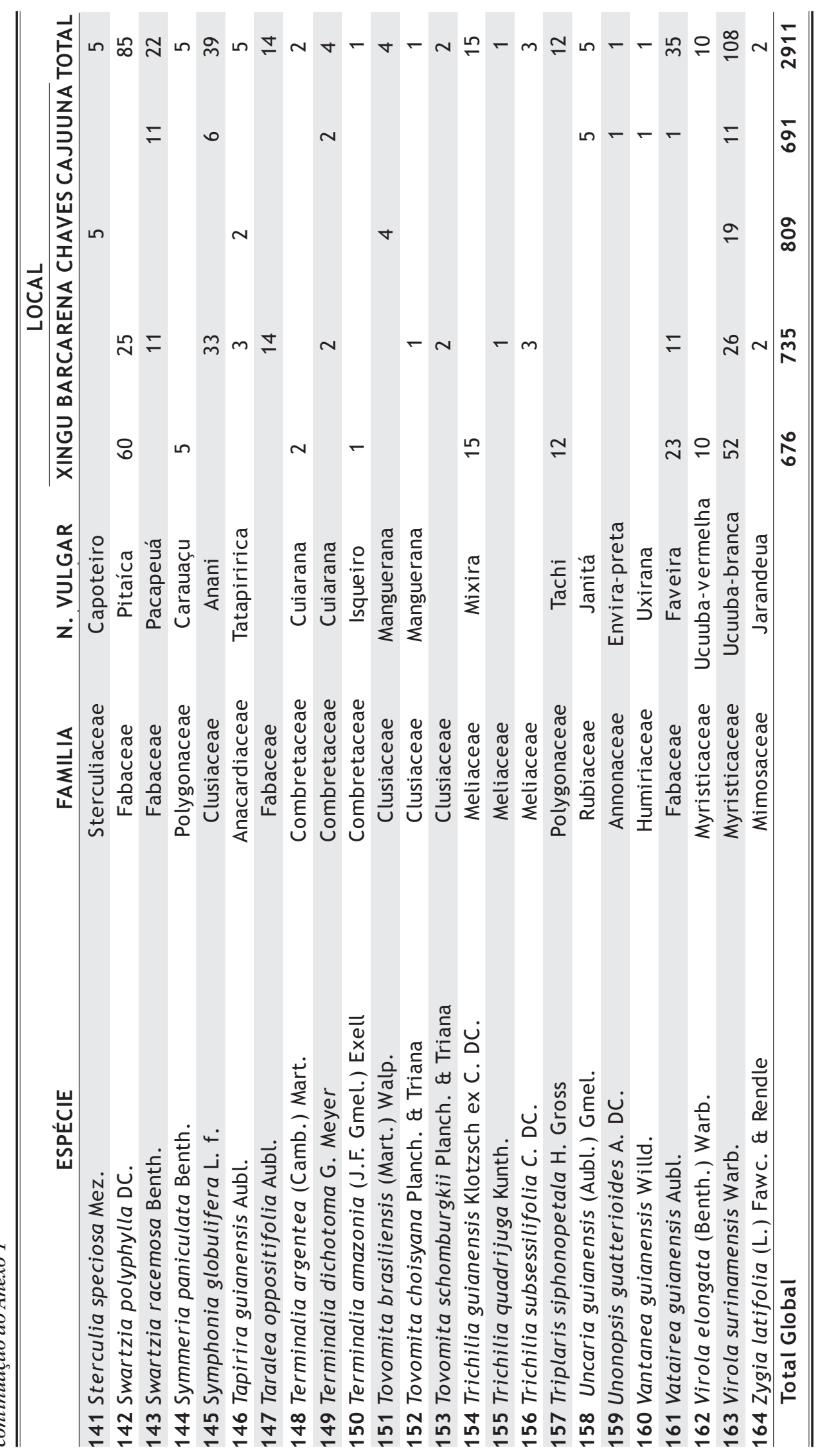

